\title{
Inbalt des Bandes
}

Tugent Spyl . . . . . . . . . . . . . 1-115

Anhang. Briefe des Magister Jobann Winckel . . . . 117-125

Nacbwort des Herausgebers . . . . . . . . . . 127-164 


\author{
Ausgaben Deutscher Literatur \\ des XV. bis XVIII. Jahrhunderts \\ unter Mitwirkung von Käthe KAHLENBerG \\ herausgegeben von HaNS-Gert RoLOFF
}

\author{
Johann Rist \\ Sämtliche Werke \\ Unter Mitwirkung von Helga Mannack \\ herausgegeben von Eberhard MaNnack (Berlin)
}

Johann Rist, Pfarrer in Wedel, gehört zu den bedeutendsten Mitgliedern der Fruchtbringenden Gesellschaft, die die Pflege der deutschen Sprache als ihre vornehmste Aufgabe ansah. Auch die Nürnberger nahmen den gelehrten Dichter, der als Pfarrherr der holsteinischen Gemeinde seine auf der Universität begonnenen medizinischen und physikalisch-chemischen Studien fortsetzte und mit bedeutenden Gelehrten und Potentaten der Zeit in Verbindung stand, in ihren Blumenorden auf. Er selbst stiftete 1660 den Elbschwanenorden. Bekannt ist Rist vor allem als Verfasser von Kitchenliedern; im heutigen evangelischen Gesangbuch finden sich noch sieben seiner Liedtexte. Von nachhaltigem Einfluß auf die zeitgenössischen Dichter waren insbesondere seine Friedensspiele, die am Ende des dreißigjährigen Krieges gedruckt wurden. Weniger Beachtung fand bislang sein 1634 veröffentlichtes Drama Perseus, das als eines der ersten selbständigen deutschen Dramen nach Erscheinen der Opitzschen Poetik einer gerechten Würdigung bedarf.

Die ersten Bände der kritischen Ausgabe des Gesamtwerkes von Johann Rist enthalten die dramatischen Dichtungen. Eine zweite Gruppe umfaßt Rists geistliche und weltliche Lyrik, an die sich die Prosaschriften, Abhandlungen und Ubersetzungen des Autors anschließen. Eine Sammlung seiner Briefe ist dem Schlußband vorbehalten. Zum besseren Verständnis der Texte sollen die Realienbände beitragen, die einen ausführlichen Kommentar zu den einzelnen Werken enthalten und darüber hinaus über die Stellung des Dichters innerhalb des Barockzeitalters Auskunft geben.

$$
\text { Es liegt vor: }
$$

Band I Dramatische Dichtungen (Irenaromachia Perseus) Mit 2 Taf. IV, 289 Seiten. 1967. Ganzleinen DM 76,-

\title{
Walter de Gruyter \& Co • Berlin 30
}




\section{Ausgaben Deutscher Literatur}

des XV. bis XVIII. Jahrhunderts

unter Mitwirkung von Käthe KahLENBERg

herausgegeben von HANS-GERT ROLOFF

\section{Georg Wickram \\ Sämtliche Werke \\ herausgegeben von HaNS-Gert ROLOFF (Berlin)}

Die Neuausgabe unterscheidet sich von der alten, in kleiner Auflage erschienenen Ausgabe, die Johannes Bolte 1901-1906 in der Bibliothek des Literarischen Vereins veranstaltet hatte, durch eine modifizierte Disposition und durch eine größere Vorlagentreue. Die einzelnen Bände enthalten jeweils den kritisch revidierten Text und ein Verzeichnis der Varianten derjenigen Drucke, die zu Lebzeiten des Autors erschienen sind. Alle weiteren editorischen Beigaben wie Überlieferungsgeschichte, Bibliographie, Biographie, Kommentar, Glcssar usw. sind dem die Ausgabe abschließenden Realienband vorbehalten. Interpunktion und Orthographie der Vorlage wurden beibehalten; von einer modernen Absatzgliederung wurde abgesehen. Auch die Illustrationen werden vollständig aufgenommen, denn sie gehören - mehr als man gemeinhin annimmt - zum richtigen Verständnis dieser Texte. - Erfreulich ist, daß der Herausgeber bei seiner Suche nach den heute noch vorhandenen Wickram-Drucken ein Spiel gefunden hat, das bisher der Wickram-Forschung völlig unbekannt war; es handelt sich um Ein Scbones / Vnd auch Cbristenliches Spyl / auß den geschichten der Aposteln ... (1552).

\section{Aufbau der Ausgabe:}

I Ritter Galmy (1539). - II Gabriotto und Reinhart (1551). - III Knabenspiegel (1554) / Dialog vom ungeratenen Sohn (1554). - IV Von guten. und bösen Nachbarn (1556). - V Der Goldfaden (1557). - VI Der irr reitende Pilger (1556). - VII Rollwagenbüchlein (1555). - VIII Die sieben Hauptlaster (1556). - IX Losbuch (1539)/ Dialog von der Trunkenheit (1555). - X Fastnachtspiele. - XI Der verlorene Sohn (1540) / Tobias (1551). - XII Apostelspiel (1552) / Der jungen Knaben Spiegel (1554). - XIII Ovids Metamorphosen (1545). - XIV Realienband.

\section{Es liegen vor: \\ Band I Ritter Galmy}

Mit 1 Taf. u. Abb. VI, 338 Seiten. 1967. Ganzleinen DM 92,Band II Gabriotto und Reinhart

Mit Textabb. VI, 297 Seiten. 1967. Ganzleinen DM 76,Band XII Apostelspiel - Knaben Spiegel

Mit Abb. IV, 281 Seiten. 1967. Ganzleinen DM 72,Band III-V sind in Vorbereitung 
Ausgaben Deutscher Literatur des XV. bis XVIII. Jahthunderts

unter Mitwirkung von Käthe Kahlengerg herausgegeben von Hans-Gert RolofF

\section{In Vorbereitung:}

JohanNes Reuchlin (1455-1522), Werke. Etwa 8 Bände JohanN BeER (1655-1700), Sämtliche Werke JohanN Christoph GotTsChed (1700-1766), Ausgewählte Werke

Johann Geiler von Kaisersberg (1445-1510), Werke

Der Patriot (1724-1726). 3 Bände

Philipp von Zesen (1619-1689), Sämtliche Werke Pamphilus Gengenbach (gest. 1524), Werke

Wolfhart Spangenderg (ca. 1570-1636), Werke

Johannes Agricola (etwa 1494-1566),

Tragedia Johannis Huss (1537)

JohanN Vogelsang (d. i. Cochlaeus), Ein heimlich

Gespräch von der Tragedia Johannis Hussen (1538)

Johannes Chryseus, Hofteufel (1545)

Alexander Seitz (etwa 1470-1540), Ein Tragedi ... Vom großen Abentmal und den zehen Junckfrawen (etwa 1540)

Gabriel Rollenhagen (1538- etwa 1622), Amantes amentes. Das ist Ein sehr Anmutiges Spiel von der blinden Liebe (1609) 

